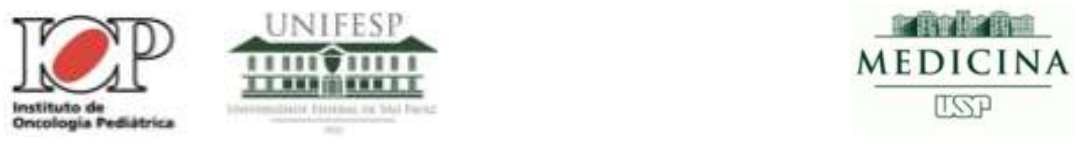

\title{
Balanced crystalloids versus saline for perioperative intravenous fluid administration in children undergoing neurosurgery: a randomized clinical trial
}

\author{
Mariana F Lima, Suzana Teruya, Luís Eduardo Martins, Paolo Pelosi, Luiz Marcelo Malbouisson
}

\section{Objectives}

To assess the effects of a balanced crystalloid solution versus saline on metabolic profile and brain relaxation in children undergoing neurosurgery

\section{Design}

A prospective, randomized, single-center, open trial

\section{Setting}

Operating room and pediatric intensive care unit in an university teaching hospital

\section{Patients}

49 children aged between 6 months and 12 years

\section{Intervention}

Patients were randomized in a 1:1 ratio to receive a balanced crystalloid (Plasma-Lyte) or saline during brain tumor resection and $24 \mathrm{~h}$ postoperatively

\section{Measurements}

Serum electrolyte and arterial blood gas analyses were performed at the beginning of surgery, after surgery, and at postoperative day 1 . Brain relaxation score was assessed by the neurosurgeon after dura-mater opening. Primary outcome: post-preop $\Delta \mathrm{Cl}^{-}$(absolute difference in serum chloride concentrations measured after surgery and at baseline).

\section{Results}

Saline versus balanced crystalloid infusion resulted in:

- increased ${ }_{\text {post-preop }} \Delta \mathrm{Cl}[6(3.5 ; 8.5)]$ vs [0 (-1.0; 3.0) $\left.\mathrm{mmol}^{-1} ; p<.001\right]$

- increased post-preop $\Delta$ base excess [-4.4 (-5.0; $2.3)$ vs $\left.-0.4(-2.7 ; 1.3) \mathrm{mmol} \mathrm{I}^{-1} ; p<.001\right]$

- increased hyperchloremic acidosis incidence $[17 / 25(68 \%)$ vs $5 / 24(21 \%) ; p<.01]$

- Comparable brain relaxation score between groups.

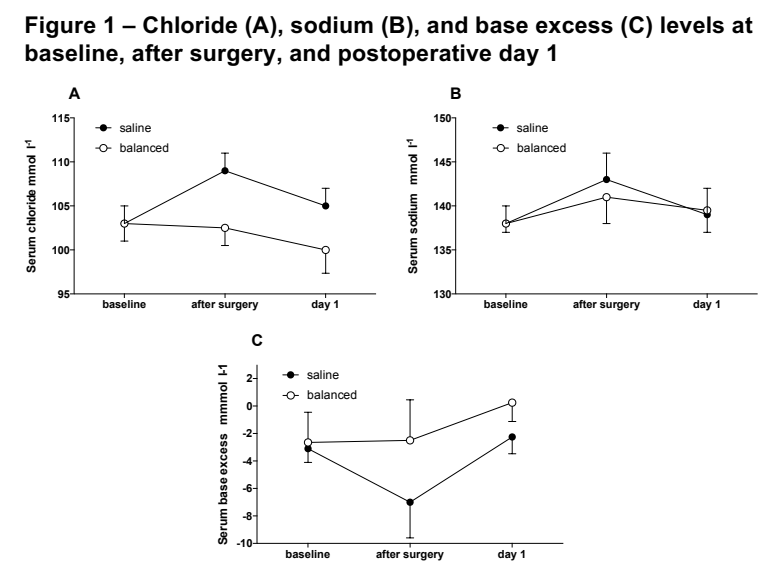

Figure 2 - Brain relaxation score

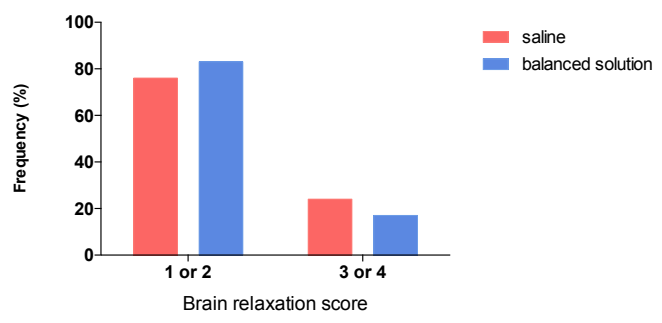

Legend: 1 , slack brain; 2 , mild brain herniation; 3 , moderate brain herniation; 4, severe brain herniation

\section{Conclusion}

In children undergoing brain tumor resection, saline infusion increased variation in serum chloride compared to balanced crystalloid. These findings support the use of balanced crystalloid solutions in children undergoing brain tumor resection 